\title{
O Trabalho do Professor em Propostas do PNLD de Ensino de língua Portuguesa
}

\author{
Ana Lúcia Horta Nogueira' \\ Maísa Alves Silva" \\ Silmara Regina Colombo"
}

'Universidade Estadual de Campinas (UNICAMP), Campinas/SP - Brasil "Universidade de São Paulo (USP), Ribeirão Preto/SP - Brasil

RESUMO - O Trabalho do Professor em Propostas do PNLD de Ensino de Língua Portuguesa. O artigo problematiza como algumas propostas do Programa Nacional do Livro Didático (PNLD) podem constituir e impactar o trabalho do professor. A partir de breve retomada histórica dos programas PNLD e PNLD - Dicionários e da análise do contexto de produção dos livros didáticos, discute-se como tais propostas foram concretizadas e são atualmente apresentadas. A análise de atividades dos livros didáticos do $1^{\circ}$ ano do ensino fundamental e do PNLD - Dicionários para o $5^{\circ}$ ano e de orientações ao professor indicam o distanciamento com relação ao trabalho docente e sugerem a necessidade de repensar as propostas, a fim de que possam contribuir para o processo de elaboração de conhecimento pelo aluno, bem como para a organização do trabalho docente.

Palavras-chave: Programa Nacional do Livro Didático (PNLD). PNLD Dicionários. Contexto de produção. Trabalho do Professor.

ABSTRACT - The Teacher's Work in PNLD (Brazilian Textbook Program) Proposals Regarding the Portuguese Language Teaching. This study discusses how some proposals of Programa Nacional do Livro Didático (PNLD - Brazilian Textbook Program) reflect, represent and influence the teacher's work. Through a brief history of PNLD and PNLD-Dicionários (PNLD Dictionaries), as well as a discussion about the context of textbooks production, it aims at understanding how such proposals were developed and are currently presented. The analyses of $1^{\text {st }}$ grade textbooks, $5^{\text {th }}$ grade dictionaries and guidance for the teachers indicate a gap between the textbooks' orientations and the teacher's work, and the necessity of reconsidering and reformulating the proposals, so that they can contribute for the knowledge development by the student and the organization of the teacher's work. Keywords: Brazilian Textbook Program (PLND). PNLD Dictionaries. Production Context. Teacher's Work.

Educação \& Realidade, Porto Alegre, v. 43, n. 1, p. 313-336, jan./mar. 2018. 313 http://dx.doi.org/10.1590/2175-623665370 


\section{Introdução: os livros didáticos medeiam o trabalho do professor?}

Atualmente, todas as escolas públicas brasileiras recebem livros do Programa Nacional do Livro Didático (PNLD), composto por diferentes materiais e propostas, tais como livros didáticos, paradidáticos, dicionários e guias para o professor ${ }^{1}$, sendo o Guia de Livros Didáticos PNLD e o Guia Dicionários em Sala de Aula exemplos desses materiais. Além da presença praticamente constante em sala de aula, fato que já justificaria o estudo do programa, os livros didáticos e os guias para os professores se constituem como objeto de nossa atenção devido à centralidade que ocupam na organização do trabalho educativo realizado pelo professor, na medida em que veiculam uma determinada seleção e sequência do conteúdo a ser ensinado, sugerem procedimentos metodológicos, geram expectativas de percursos e ritmos de aprendizagem (Silva; Nogueira, 2015).

Diante desse cenário e cientes de que a presença maciça desses materiais pode ser fator de risco para reduzir o protagonismo do professor na organização do trabalho educativo, o propósito deste texto é conhecer o teor das orientações de alguns manuais e livros didáticos e problematizar suas implicações para o trabalho docente.

Entendemos que o trabalho do professor é mediado por “[...] instrumentos materiais ou simbólicos, na medida em que o trabalhador se aproprie de artefatos socialmente construídos e disponibilizados para ele pelo meio social" (Machado, 2007, p. 91). Dentre os inúmeros instrumentos que medeiam a atividade de ensino, ao lado das crenças e das concepções, teorias e propostas do campo da metodologia de ensino e didática e da tradição profissional (Amigues, 2004), as orientações dos livros didáticos ocupam um lugar privilegiado nesse processo, devido a sua presença marcante e, talvez, pelo detalhamento e pela sistematização das atividades apresentadas.

Assim, entre os autores e editores de livros didáticos e os professores e profissionais da educação, estabelece-se uma dinâmica quase perversa: à medida que os programas e livros didáticos passam a elaborar e detalhar a sequência e o formato das atividades de ensino, os professores vão, pouco a pouco, sendo destituídos do trabalho de concepção e organização do ensino. Levando essa dinâmica ao extremo, o detalhamento das orientações apresentadas ao professor pode nos colocar diante de duas situações:

[...] de um total ocultamento ou negação do trabalho do professor, [...] ou diante da construção de sua 'figura' como um simples adjuvante ou instrumento de um processo que se apresenta como tendo um caráter inelutável e quase mecânico, pois bastaria que o professor aplicasse os princípios sugeridos pelas prescrições para que os objetivos da atividade fossem alcançados (Machado; Abreu-Tardelli, 2009, p. 113-114). 
Ainda como efeito dessa dinâmica, temos a reiteração de que o trabalho do professor possa estar restrito a seguir as orientações e prescrições dos instrumentos, desconhecendo que a complexidade da atividade de ensino está justamente na contínua seleção, transformação e reelaboração das orientações e dos meios de trabalho, de forma articulada às necessidades e características de cada um de seus alunos (Clot, 2006; Machado, 2007). Ou seja, “[...] a atividade de concepção e organização de um meio de trabalho é certamente orientada para a atividade dos alunos, mas também para o professor, que vai ser o executor de sua própria concepção" (Amigues, 2004, p. 45).

E é esse entendimento de complexidade da atividade profissional que sustenta, neste artigo, nossa opção de considerar as implicações das orientações dos manuais e dos livros didáticos. Em análise acerca da produção científica sobre o tema, Batista e Rojo (2008, p. 43) apontam como os livros escolares passam a ser tomados como objeto de estudo.

\begin{abstract}
Objeto de natureza complexa, resultante de um processo de produção que envolve dimensões econômicas, técnicas, sociais, políticas e educacionais, a literatura escolar demanda e enseja o estudo dessas diferentes dimensões. Apesar do surgimento recente de novas temáticas e abordagens metodológicas, a fixação do interesse da pesquisa brasileira sobre apenas uma dessas dimensões - sobre a educacional e, particularmente, sobre sua faceta didática, em seus conteúdos e metodologia - dá mostras, portanto, da necessidade de superar esse forte desequilíbrio e de atribuir à literatura escolar um estatuto específico, vale dizer, da necessidade de tomar esse fenômeno não apenas como meio para o estudo de conteúdos e de metodologia de ensino, mas como objeto de investigação.
\end{abstract}

É exatamente no espaço indicado pelos autores, tomando os livros didáticos como objeto de investigação, que procuramos inscrever nossas reflexões acerca de algumas propostas do PNLD.

O PNLD é um programa do Fundo Nacional de Desenvolvimento da Educação (FNDE) responsável pela avaliação, seleção e distribuição de livros didáticos e paradidáticos para todas as escolas públicas brasileiras. Além da distribuição dos livros, o programa também se desdobra em outras propostas, entre elas, o PNLD Dicionários. Dados o grande alcance e capilaridade do programa, consideramos fundamental compreender como as propostas que chegam à escola afetam o trabalho e a autonomia do professor.

Assim, para efeitos deste artigo, propomos retomar as orientações dirigidas ao professor em atividades para o $1^{\circ}$ ano do ensino fundamental (EF), voltadas ao processo de alfabetização, em alguns livros didáticos selecionadas pelo PNLD 2013, e as orientações de propostas para o $5^{\circ}$ ano do EF pelo Guia Dicionários em Sala de Aula (Rangel, 2012), que integra o PNLD Dicionários. 


\section{PNLD e PNLD Dicionários: breve histórico dos programas}

Acredita-se ter sido no ano de 1929 o surgimento do embrião do que hoje conhecemos como PNLD (Freitag; Motta; Costa, 1989), com outra denominação e com diferente forma de execução. Nessa data foi criado o Instituto Nacional do Livro na tentativa de dar maior legitimidade ao livro didático nacional, bem como ampliar a sua produção. Com o intuito de controlar a produção e a circulação do livro didático no Brasil, em 1938, foi criada a Comissão Nacional do Livro Didático CNLD (Batista, 2003). A partir de então, os programas do governo federal para o livro didático foram aperfeiçoados e ganharam novos formatos até que, no ano de 1985, foi instituído o PNLD, com a denominação que conhecemos hoje, mas ainda com execução diferente da atual.

Desde seu princípio, os programas do Estado voltados ao livro didático sempre tiveram como intuito aperfeiçoar a produção dos livros didáticos, bem como regulamentá-la. O que não muda desde sua criação, porém, é a participação de editoras privadas e a escolha dos livros por parte dos professores (escolha relativa, que não é sempre respeitada). Já em relação aos dicionários, nas duas últimas edições do programa - 2006 e 2012 -, as obras chegaram às escolas em acervos prontos, sem que o professor tivesse a oportunidade de escolha.

O atual formato do PNLD foi elaborado em 1996, quando o Ministério da Educação (MEC) instituiu o processo de avaliação dos livros didáticos disponibilizados para as escolas públicas. O processo de inscrição e seleção dos livros didáticos no programa ocorre da seguinte forma: conforme previsto em edital de inscrição, com as características, as regras e os critérios de avaliação do programa, as editoras inscrevem suas obras, que passam por processo de avaliação realizado sob a coordenação da Secretaria da Educação Básica do MEC $^{2}$. Somente as obras aprovadas passam a ser descritas pelo Guia do Livro Didático, e apenas os livros didáticos que integram este documento podem ser escolhidos pelos professores e enviados pelo MEC para as escolas públicas de todo o país.

A questão da 'qualidade' do livro didático, defendida pelo Ministério da Educação, é bem explícita: como garantia da 'boa escolha' pelo professor, o sistema de ensino (representado pelo MEC) realiza uma 'pré-seleção' desse material. O resultado pode ser conferido no Guia do Livro Didático (Brasil, 2001), que contém resenhas de todos os livros recomendados, agrupadas por áreas do conhecimento (Martins; Sales; Souza, 2009, p. 16).

Desde sua criação, o PNLD tem passado por mudanças relacionadas aos critérios de avaliação, à abrangência e à extensão (no início do programa, apenas livros das séries iniciais do EF eram avaliados; atualmente, todos os níveis da educação básica são atendidos, com exceção da Educação Infantil), bem como ganhando novas modalidades, como o PNLD Dicionários que, no ano de 2000, reincluiu os dicionários em programas oficiais de materiais didáticos após quase duas décadas de ausência.

316 Educação \& Realidade, Porto Alegre, v. 43, n. 1, p. 313-336, jan./mar. 2018. 
A inclusão de dicionários no programa foi considerada pertinente, pois o "conhecimento sistematizado sobre o léxico que o dicionário proporciona tem um papel relevante a desempenhar na (re)construção escolar do conhecimento sobre a língua e a linguagem" (Rangel, 2012, p.18). De fato, por mais que as concepções sobre o ensino da linguagem se afastem do consenso entre linguistas e gramáticos, há um ponto em que não há divergências: todos concordam com a importância dos dicionários como apoio à aprendizagem tanto de língua materna quanto de língua estrangeira.

Nas edições de 2000 a 2004, as obras lexicográficas eram inscritas e avaliadas nos mesmos moldes das opções disponibilizadas para o livro didático, com a distribuição de um minidicionário por aluno, de acordo com o título escolhido pela escola. Dentre os dicionários aprovados nesse período, destacou-se o Mini Aurélio Século XXI Escolar (Ferreira, 2001), o único classificado no Guia de Livros Didáticos como "recomendado com distinção" por apresentar, entre outras características "linguagem simples e precisa", "boa seleção vocabular" e também porque na obra "não se notam preconceitos" (Brasil, 2003, p. 35). Assim, o Mini Aurélio, com cerca de 30.000 verbetes, passou a ser sinônimo de dicionário escolar ao ser adotado pela grande maioria das escolas públicas brasileiras guiadas pela classificação que o dicionário recebeu no Guia, considerado como obra em total conformidade com os critérios de análise comuns e específicos utilizados pelo Programa.

No entanto, contrariando as expectativas oficiais, foi observado desuso generalizado desses dicionários na escola. Por serem concebidas para público adulto já escolarizado, as obras exigiam do aluno do Ciclo I do EF as habilidades de um usuário experiente. Além disso, a definição lexicográfica clássica é pouco amigável até mesmo para o público letrado e experimentado em consultas. Outro obstáculo foi a inexistência de tradição escolar de uso sistemático do dicionário, impedindo que muitos professores, ainda que motivados, assumissem o desenvolvimento da proficiência em consulta como um necessário conteúdo de ensino. Direta ou indiretamente, esse quadro geral esteve na base das mudanças introduzidas no PNLD 2006, que estabeleceu parâmetros para a elaboração de dicionários mais comprometidos com o perfil do aluno e os objetivos do primeiro segmento do EF (Rangel, 2011).

Com a reformulação do PNLD Dicionários efetivada em 2006, mantida na edição seguinte de 2012, a distribuição de um minidicionário por aluno foi substituída pela adoção de acervos lexicográficos, entre três e sete títulos por acervo/turma, com obras adaptadas ao nível de ensino, acompanhadas do guia com funções de Manual do Professor. Com isso, os dicionários que antes eram disponibilizados como material individual para uso do aluno, tanto na escola quanto em casa, passaram a ficar disponíveis apenas no ambiente escolar e em número reduzido de volumes para uso coletivo, o que obriga o professor a fazer empréstimos de acervos de outras turmas quando o objetivo é o trabalho com todos os alunos. 
Ou seja, dentro das duas últimas edições do PNLD Dicionários, no lugar de um dicionário por aluno, sempre com o mesmo título, o MEC considerou mais ajustado às demandas escolares, distribuir acervos formados por dicionários, para uso coletivo na escola, de editoras diferentes, que apresentam atualmente as seguintes categorias:

- Tipo 1: três títulos de 500 a 1000 verbetes para o $1^{\circ}$ ano do EF;

- Tipo 2: sete títulos de 3000 a 15000 para o período entre o $2^{\circ}$ e o $5^{\circ}$ ano do EF;

- Tipo 3: cinco títulos de 19.000 a 35.000 para o segundo segmento do EF;

- Tipo 4: quatro títulos de 40.000 a 100.000 para o ensino médio.

Desse modo, tendo em vista os títulos aprovados para compor o Guia de Livros Didáticos, a composição do acervo de dicionários e, principalmente, as orientações formuladas para o professor, passamos agora a discutir o contexto de produção dos materiais para compreender as possibilidades que oferecem para o trabalho docente.

\section{Por que Analisar o Contexto de Produção dos Livros Didáticos?}

Em estudo sobre coleções de livros didáticos, Lerner (2004) propõe como categorias de análise a concepção do objeto de ensino, a representação do aluno como sujeito de aprendizagem e a representação do professor como destinatário das orientações e prescrições do manual do professor.

Considerando, portanto, a última categoria, é relevante destacar que, por meio da análise do contexto de produção de livros didáticos, foi possível explicitar as concepções que veiculam, mas acima de tudo, explicitar os diferentes destinatários e as vozes presentes nas orientações ao professor: em que contexto de produção os livros didáticos e os manuais para o professor são produzidos? A que outros textos se articulam e respondem? (Machado, 2007).

Falar sobre livros didáticos, PNLD e seus desdobramentos requer análise mais abrangente que o próprio livro em si, pois a partir do contexto mais amplo, é possível elaborar hipóteses sobre os autores na situação de produção mais imediata (Ferreira, 2011). Dessa forma, é fundamental analisar o contexto de produção no qual está inserido e explicitar as diferentes vozes e interlocutores que circulam dentro desses livros. A análise do contexto de produção dos livros didáticos permite vê-los de modo dialético, destacando o caráter integrativo, interacional e multidimensional das práticas educacionais (Saujat, 2004).

Não olhamos o livro pelo livro, mas o livro dentro da sociedade, como parte de um programa que se desdobra em diferentes propostas, marcado por formas de representação de escola, de professor, de processo ensino-aprendizagem. Focalizamos, assim, o contexto de produção de livros didáticos, processo que envolve autores e editores que

318 Educação \& Realidade, Porto Alegre, v. 43, n. 1, p. 313-336, jan./mar. 2018. 
respondem ao edital do PNLD, regido por específicas normas para inscrição e avaliação das coleções.

As condições de produção do PNLD Dicionários são um pouco distintas. Após a definição dos acervos de cada tipo, as sugestões de atividades são elaboradas por autores convidados pelo MEC para compor o Guia Dicionários em Sala de Aula, marcado pelas concepções e pelos fundamentos por eles assumidos. Nesse caso, o professor não é chamado a fazer uma escolha, uma vez que os acervos já estão previamente definidos e o guia é único. Nessa situação, o MEC assume as prerrogativas de elaboração de um único programa a ser proposto e implementado nas escolas públicas brasileiras, o que não garante o estabelecimento de relações complementares com os livros didáticos indicados pelos professores dentre os aprovados pelo PNLD.

Considerando, portanto, o processo de avaliação das coleções seleção do acervo de dicionários e elaboração de orientações para os professores - destacamos a presença de diferentes esferas, diferentes sujeitos, que elaboram propostas educativas e orientações para o professor, diferentes falas sobre o livro didático. Sujeitos que representam e falam sobre o livro, de modo que suas diferentes vozes ecoam em sua constituição, resgatando enunciados já ditos e renovando-os, de modo a reforçar determinadas visões acerca do funcionamento escolar e de seus integrantes. Assim,

\begin{abstract}
[...] aquilo de que nós falamos é apenas o conteúdo do discurso, o tema de nossas palavras. [...] Mas o discurso de outrem constitui mais do que o tema do discurso, ele pode entrar no discurso e na sua constituição sintática, por assim dizer, 'em pessoa', como uma unidade integral da construção. Assim, o discurso citado conserva sua autonomia estrutural e semântica sem nem por isso alterar a trama linguística do contexto que o integrou (Bakhtin, 2004, p. 144).
\end{abstract}

Entendemos que os discursos são permeados pelo discurso de outros, por outras vozes, são polifônicos. As vozes dos avaliadores e do edital do PNLD estão dialogicamente presentes nos livros didáticos e perpassam as propostas e orientações, em intenso diálogo com os autores e todo o corpo editorial. Logo, neste contexto de produção, todos os interlocutores participam do discurso polifônico sobre o livro didático e demais modalidades do programa. Com quem o autor/editor dialoga? Seu interlocutor primeiro, real, é o professor? Ou o professor seria o destinatário suposto, sendo que o real é a comissão de avaliadores do PNLD? Como o professor é representado nesse processo? Quem é o professor, para que o autor/editor se dirija a ele de determinada forma? O que o autor/editor pretende quando fala com o professor/avaliador de determinada forma? (Geraldi, 1997).

No processo de análise das coleções, percebe-se a presença de diversos destinatários; mesmo quando as orientações do livro didático se dirigem ao professor, estão voltadas aos avaliadores do PNLD, como resposta aos requisitos do edital de inscrição. Antes mesmo de se mostrar 
atrativa e interessante para que o professor escolha uma determinada coleção, os autores e editores estão concentrados em obter a aprovação do PNLD, condição para chegar à escola para uma possível indicação dos professores. Com relação ao PNLD Dicionários, discute-se a falta de articulação entre os materiais que compõem o mesmo programa, que inclui o livro didático, os dicionários dos acervos e o Guia Dicionários em Sala de Aula. O Guia propõe atividades que não se adequam ao reduzido número de entradas dos dicionários de tipos 1 e 2, além de sugerir que as atividades propostas sejam complementadas com o livro didático que raramente traz atividades que requerem a consulta ao dicionário.

Destacamos, assim, a complexa dinâmica entre autores, editoras, avaliadores do PNLD e professores em seu trabalho. Dinâmica ainda mais intricada se lembrarmos dos interesses comerciais presentes. É importante ressaltar o expressivo crescimento do volume de livros produzidos no Brasil nas últimas décadas, quando parte significativa do mercado editorial se volta à elaboração e oferta de livros didáticos para atender aos programas do governo federal, produzindo algumas distorções e problemas ${ }^{3}$.

Os programas governamentais de aquisição de livros didáticos têm enorme importância para o mercado editorial brasileiro. Estimativas apontam que a indústria dos didáticos representa cerca de $54 \%$ da indústria nacional de livros. No que tange à concentração do segmento, tem-se, do lado da demanda, um quase monopsônio (no ensino fundamental, por exemplo, o Estado responde pela aquisição de aproximadamente $90 \%$ dos livros publicados); do lado da oferta, configura-se um oligopólio (poucas editoras vêm concentrando o maior volume de compras do FNDE ao longo do tempo) (Britto, 2011, p. 12).

Como podemos constatar a partir dos dados acima apresentados, as editoras têm grande interesse em ter suas obras aprovadas pelo PNLD, dada a garantia de venda de número significativo de exemplares quando escolhidas pelos professores. Essa cadeia de interesses conflituosos - com diferentes expectativas por parte dos gestores e avaliadores do PNLD, dos autores e editores dos livros - pode resultar no desconhecimento dos interesses e das necessidades dos professores para desenvolver práticas educativas em sala de aula adequadas às condições reais.

Pensar as relações entre essas diversas esferas auxilia a compreender o processo de produção dos livros didáticos e de elaboração das orientações para o professor. Assim, tendo como pano de fundo o contexto de produção das propostas do PNLD aqui indicadas, passamos agora à discussão de algumas orientações e de suas implicações para o trabalho do professor. 


\section{As Orientações dos Manuais e o Trabalho do Professor}

Em pesquisa recém-concluída (Silva, 2015), trazemos a análise dos manuais didáticos de quatro coleções aprovadas no PNLD - 2013 destinadas ao $1^{\circ}$ ano do EF. Cada uma delas pertencente a um dos quatro grandes agrupamentos indicados pelo Guia, que divide as obras levando em conta o tempo de alfabetização previsto em cada livro. Nossas análises permitiram entender que os livros didáticos seguem a seguinte lógica: embora o professor apareça como interlocutor declarado e nomeado nos enunciados do manual didático, esse lugar também é preenchido por outros interlocutores aos quais os autores procuram responder e convencer. Ou seja, o primeiro leitor/interlocutor dos livros, aquele que aprova, que os inclui na lista dos livros indicados e os legitima, são os avaliadores do PNLD. Temos entendido, assim, que o professor é o suposto destinatário dos livros didáticos, enquanto os destinatários reais são os avaliadores do PNLD.

Os autores e editores dos livros didáticos se preocupam em responder às exigências desses interlocutores para que a coleção didática seja aprovada dentro dessa imensa relação de vozes e de discursos. $\mathrm{O}$ que encontramos nos manuais é uma resposta ao que já se discursivizou acerca do funcionamento da escola e do trabalho docente, processo dialógico no qual o professor permanece idealizado e marginalizado, sem se tornar o principal interlocutor.

Nossas análises sugerem que os próprios manuais dos livros didáticos voltados ao professor já procuram atender as exigências do edital de inscrição, ao apresentar ao professor os temas já destacados pelos autores dos livros didáticos, em consonância com os critérios de avaliação apresentados no Guia. Nesse contexto, aquilo que os autores indicam aos professores é intensamente marcado pelas ênfases do documento, como pode explicitar a análise de um trecho do Guia de Livros Didáticos PNLD 2013, ao listar os requisitos para a estruturação do manual do professor, e de um trecho do sumário do Livro do Professor da coleção Viraver, por nós analisada. 
Figura 1 - Trecho do Item Princípios e Critérios Estabelecidos Para a Avaliação das Coleções de Língua Portuguesa Destinadas ao EF

\begin{tabular}{|l|}
\multicolumn{1}{c|}{ Manual do Professor } \\
O Manual ou Livro do Professor deve constituir-se como um instrumento capaz de \\
subsidiar adequadamente o uso da coleção pelo professor, tanto no trabalho de sala \\
de aula quanto na orientação para o estudo autônomo por parte do aluno. \\
Não pode, portanto, ser meramente uma cópia do livro do aluno, com as respostas \\
preenchidas. Deve, por isso: \\
- explicitar com clareza e correção os pressupostos teóricos e metodológicos a \\
partir dos quais a proposta didático-pedagógica foi elaborada; \\
- descrever com precisão e funcionalidade a organização dos livros, inclusive no \\
que diz respeito aos objetivos a serem atingido nas atividades propostas e aos \\
encaminhamentos necessários; \\
- apresentar subsídios para a avaliação dos resultados de ensino, assim como para a \\
ampliação e adaptação das propostas que figuram no(s) livro(s); \\
- propor formas de articulação entre as propostas e atividades da coleção e os \\
demais materiais didáticos distribuídos por programas oficiais, como o PNLD \\
Dicionários, o PNLD dos Materiais Complementares e o PNBE.
\end{tabular}

Fonte: Brasil (2013, p. 17).

Figura 2 - Sumário do Livro do Professor da Coleção Viraver

\begin{tabular}{|c|c|}
\hline \multicolumn{2}{|l|}{ SUMÁRIO } \\
\hline \multicolumn{2}{|l|}{ PROPOSTA TEÓRICO-METODOLÓGICA } \\
\hline O trabalho com a linguagem e os objetivos da coleção & 5 \\
\hline A formação do leitor e do escritor: um diálogo entre a teoria e a prática & \\
\hline - Ler para quê? Ler por quê? & 6 \\
\hline - Escrever por quê? Escrever para quê? & 7 \\
\hline A prática da leitura e da escrita & 8 \\
\hline Trabalho em grupo e aprendizagem & 9 \\
\hline \multicolumn{2}{|c|}{$\begin{array}{l}\text { OBJETIVOS DO ENSINO DE LÍNGUA PORTUGUESA NOS PRIMEIROS } \\
\text { ANOS DO ENSINO FUNDAMENTAL }\end{array}$} \\
\hline Alfabetização e letramento & 11 \\
\hline O leitor e a variedade de gêneros discursivos & 11 \\
\hline Estilos de letra: desafios à leitura e à escrita & 13 \\
\hline - Quando introduzir a escrita em letra cursiva? & 14 \\
\hline O papel dos conhecimentos prévios na apropriação da linguagem escrita & 15 \\
\hline \multicolumn{2}{|l|}{ AVALIAÇÃO } \\
\hline A ação avaliativa e a prática do professor & 16 \\
\hline - Avaliação diagnóstica & 16 \\
\hline A revisão e a reescrita do texto & 18 \\
\hline \multicolumn{2}{|l|}{ COMO O LIVRO ESTÁ ESTRUTURADO } \\
\hline Por que um tema a cada unidade? & 19 \\
\hline O texto e os intertextos & 19 \\
\hline As seções do livro e orientações sobre a prática pedagógica & 19 \\
\hline
\end{tabular}

Fonte: Miranda, Micarello e Schapper, (2012). 
Como os documentos acima indicam, em atendimento aos critérios de avaliação indicados pelo Guia, o manual do professor segue os tópicos e itens apontados como de essencial importância. Nossas análises indicam que, em vez de se dirigir ao professor e aos alunos, os editores e autores dos livros didáticos precisam responder adequadamente aos avaliadores do PNLD, ao edital e às normas dos programas para que sejam aprovados. São estes, consequentemente, os principais interlocutores e protagonistas na produção do livro escolar, e o professor, que ocupa lugar definido na concretude das condições da escola, passa para um lugar secundário.

E quais problemas isso pode acarretar ao trabalho do professor? Acreditamos que, ao escrever manuais para o professor, mas com a atenção voltada principalmente para a aprovação pelo PNLD, cria-se o descompasso entre as expectativas e aquilo que é dito ao professor e aos avaliadores do programa. Exemplificaremos com uma atividade da coleção Porta Aberta, uma das coleções por nós analisadas.

De acordo com o Guia de Livros Didáticos, é essencial que todo o manual do professor apresente a fundamentação teórica para o bom uso pelo docente, uma vez que ali o professor encontrará as concepções de ensino, aprendizagem, alfabetização, em meio a outras que guiam o livro didático com o qual está trabalhando. Para atender a essa exigência do PNLD, todos os manuais didáticos procuram trazer a fundamentação teórica. No manual do livro Porta Aberta (Bragança; Carpaneda, 2011, p. 6), para o $1^{\circ}$ ano do EF, encontramos assim posto:

\begin{abstract}
Os sons que as letras representam, isto é, as relações entre fonemas e grafemas são, por sua vez, um conhecimento fundamental. Vale destacar que, no início do processo de alfabetização, o som (o fonema) é uma realidade muito abstrata para a criança. Ela tende a lidar com unidades maiores, as quais ela ouve e consegue falar com mais facilidade. Desse modo, é compreensível que escolha usar unidades como a sílaba e mesmo as palavras.
\end{abstract}

Entretanto, no mesmo livro didático, como podemos ver na Figura 3, encontramos a seguinte atividade.

Figura 3 - Proposta de Atividade - Coleção Porta Aberta

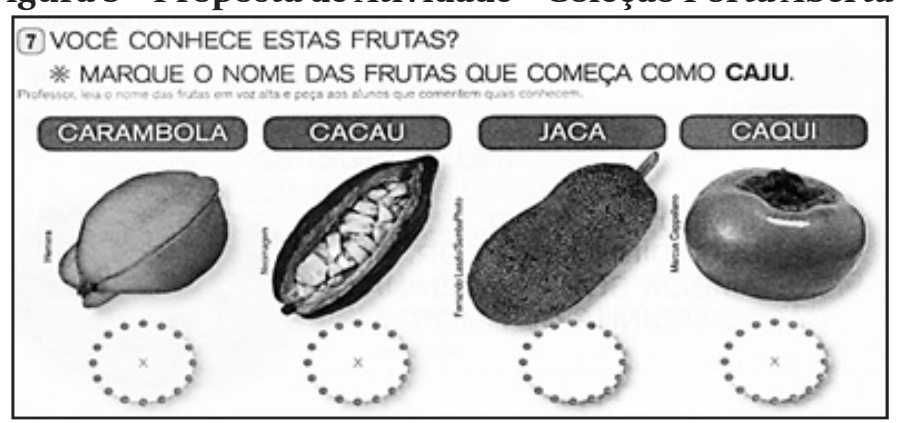

Fonte: Bragança e Carpaneda (2011, p. 52). 
Na atividade proposta, o aluno em fase inicial da alfabetização é chamado a comparar palavras - nomes de frutas - sem lidar com unidades textuais maiores, mas precisará compreender a relação grafema/ fonema, vista como algo difícil no início do processo de alfabetização, ou fazer a simples relação entre a escrita da palavra $C A J U$ com as demais frutas. Entendemos, assim, que nem sempre as informações que o professor encontra no Manual, consideradas pelo Guia de livros didáticos como importantes para a utilização do livro, serão efetivamente contempladas pelas atividades de ensino propostas.

A atividade leva a criança a comparar e reconhecer as relações entre grafemas e fonemas, aspecto fundamental durante o processo de alfabetização. Entretanto, o principal problema é o predomínio de atividades como essa, em detrimento de atividades que apresentam textos escritos. A presença de atividades como essa pode ser compreendida pelo professor como uma proposta desejável e adequada para o trabalho com a linguagem escrita e pode reiterar a ideia de que o ensino de aspectos do funcionamento da escrita prevalecem sobre suas funções e seus usos sociais.

O trabalho com os textos não pode ser deixado em segundo plano, ao contrário, deve-se dar ao aluno a oportunidade de pensar a língua em movimento, em um constante jogo entre significantes e significados, entretanto, na escola essas atividades são reduzidas à localização de rimas, de palavras que tenham sons parecidos (Romão; Pacífico, 2006). Entendemos, com tudo isso, a grande importância de levar o aluno a refletir sobre a língua e seus diversos usos, no que diz respeito aos gêneros textuais, às variações linguísticas, às especificidades da forma oral ou escrita de linguagem.

Todas as coleções por nós analisadas destacam a importância de que o aprendizado leve o aluno a refletir, interpretar e lançar olhar crítico sobre o mundo em que vive, para que o repertório do aluno seja sempre ampliado. Nesse processo, a linguagem oral também ganha certo destaque, de modo que o aluno consiga participar das mais diferentes situações comunicativas.

Vivemos em uma sociedade letrada na qual se valoriza sobremaneira as situações escritas e da norma padrão, na qual as variações linguísticas e a oralidade acabam sendo menos consideradas pela escola, que poderia privilegiar a reflexão sobre os diferentes usos da língua, mas perde boas oportunidades para que isso ocorra, tal como na proposta ilustrada na Figura 4. 
Figura 4 - História em quadrinhos - Coleção Viraver

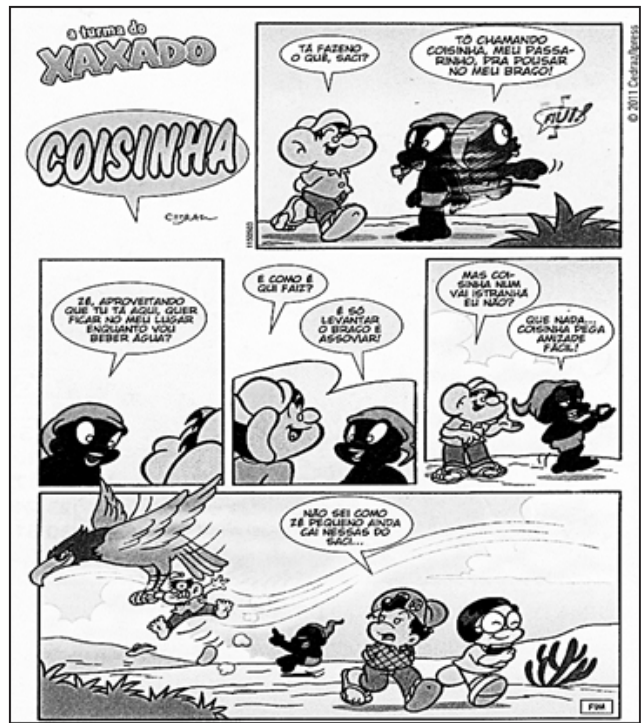

Fonte: Cedraz (2007 apud Miranda, Micarello e Schapper 2012, p. 144).

A própria orientação ao professor destaca que na história em quadrinhos são apresentados personagens regionais, nordestinos. Além disso, algumas palavras são grafadas de acordo com a linguagem oral, e muitas delas não dizem respeito apenas à pronúncia usada na região nordeste, mas à forma oral de linguagem, tais como qui, faiz, istranhá e tá, bem como algumas expressões, como ainda cai nessas do Saci.

Vemos aí uma ótima oportunidade para refletir e apreender os diversos aspectos da língua, assim como as variações, o funcionamento e o uso. Porém, como observamos abaixo na Figura 5, o livro não explora as várias possibilidades de reflexão sobre o uso da língua em diferentes situações e práticas sociais, os aspectos do funcionamento linguístico e as diferenças entre oral e escrito. 


\section{Figura 5 - Proposta de Atividade - Coleção Viraver}

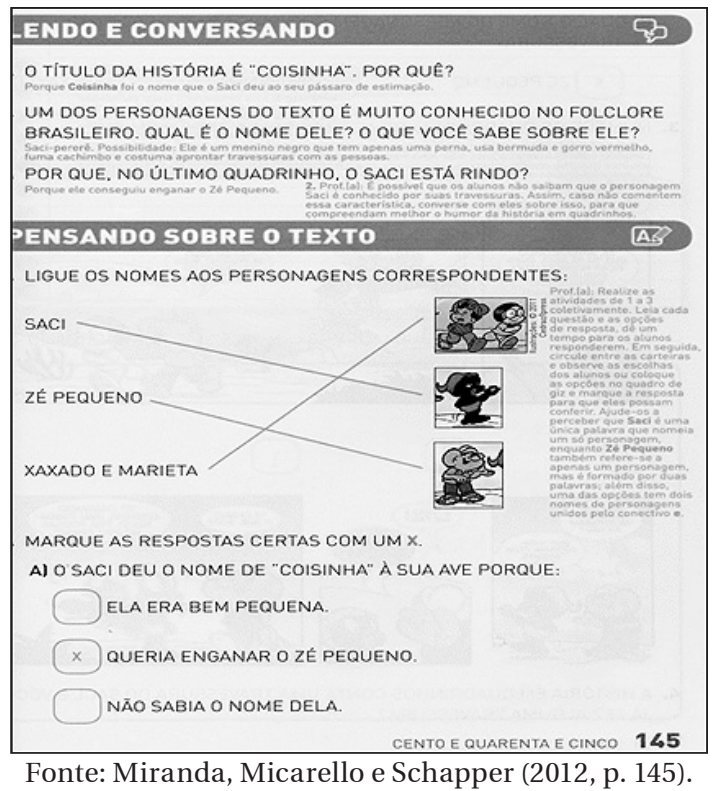

Os exercícios relacionados à história em quadrinhos não tematizam aspectos do uso social e das variações linguísticas. Ao contrário, trazem algumas questões que demandam respostas aparentemente óbvias e pouco desafiadoras para o aluno. Além disso, a escolha por atividades como essa, reduzidas ao reconhecimento da escrita do nome dos personagens, explicita uma concepção limitada e equivocada daquilo que a criança em fase de alfabetização pode aprender e realizar, como se, enquanto não souber ler, a criança só puder lidar com palavras isoladas e com determinados aspectos do funcionamento da escrita - no caso, o registro escrito do nome dos personagens - em detrimento dos aspectos textuais e discursivos da língua em funcionamento nas situações reais de uso.

Em situações como essa, muito comuns nos livros didáticos, o professor não apenas encontra a reiteração de determinadas práticas que ele já conhece, mas, acima de tudo, perde a oportunidade de conhecer outras concepções e alternativas para as práticas educativas de alfabetização. Nesse sentido, podemos dizer que a redução e a simplificação sugeridas pelo livro didático têm como efeito a legitimação de determinadas práticas de alfabetização, nas quais o texto continua sendo somente pretexto e fonte de palavras isoladas, práticas nas quais as crianças têm raras oportunidades para refletir sobre os aspectos textuais e discursivos da escrita.

Enfim, a presença constante de atividades semelhantes a essa nos livros de alfabetização e de Língua Portuguesa nos coloca diante da sutileza do problema: não se trata somente da presença dessas atividades, mas da ausência de outras propostas que tragam concepção mais ampliada acerca da escrita. 
Nogueira; Silva; Colombo

Mais uma vez, encontramos descompasso entre as pretensões sugeridas pelo livro didático e o que realmente as atividades propõem discutir e ensinar. Entendemos que isso possa ocorrer pela necessidade de que o manual se adeque às exigências do PNLD para a sua aprovação, deixando escapar questões que são de extrema importância no contexto de sala de aula, tanto no que diz respeito ao trabalho do professor, quanto ao aprendizado do aluno. Segundo as indicações do edital do programa, o manual que tem o professor como pretenso destinatário deve destacar o trabalho educativo com oralidade, práticas sociais, letramento, reflexão sobre a língua e participação nas mais diversas práticas sociais. Embora a história em quadrinhos permita explorar as variações linguísticas, isso aparece apenas de forma marginal na atividade proposta.

É justamente por olharmos o livro em seu contexto de produção e de uso em sala de aula - e não apenas olharmos o livro por ele mesmo, sua estrutura, constituição, organização, tópicos avaliados pelo o PNLD (como apresentam as resenhas de aprovação das obras didáticas) - que conseguimos perceber esses desencontros entre o que está indicado no manual e o que de fato encontramos nas atividades do livro do aluno.

A análise dos impactos do programa PNLD para o trabalho do professor é também objeto de reflexão em pesquisa na qual tematizamos o PNDL Dicionários (Colombo, 2016). Como já foi dito, além dos dicionários, todos os acervos são acompanhados pelo Guia Dicionários em Sala de Aula (Rangel, 2012), que traz aos professores um conjunto de sugestões de atividades com uso do acervo, explorando a ordem alfabética, habilidade em encontrar palavras, comparação de definições, sinonímia, palavras homônimas, ortografia, entre outros aspectos.

O principal objetivo do Guia Dicionários em Sala de Aula é subsidiar o trabalho com os dicionários dos acervos, funcionando também como espécie de manual do professor. Para isso, divide-se em duas partes. A primeira destinada a ressaltar a importância do dicionário no processo de desenvolvimento da linguagem escrita entendido como "um tipo particular de suporte da escrita - e um gênero do discurso" (Rangel, 2012, p.44) e a descrever os dicionários dos acervos que chegaram às escolas. "Que tipo de livro é exatamente o dicionário? Para que serve? Por que motivo os dicionários se tornaram objeto de políticas públicas em educação?" (Rangel, 2011, p. 50) são algumas das questões respondidas na primeira parte do manual dirigido aos professores. Ainda de acordo com o autor, é possível dizer que o PNLD induz à inclusão do desenvolvimento da proficiência em consulta ao dicionário como objeto de ensino-aprendizagem.

Já a segunda parte do guia, considera que o uso do dicionário deve ser objeto de ensino e aprendizagem na escola, pois "tanto aumenta o grau de letramento dos sujeitos quanto aprofunda o funcionamento social da escrita" (Rangel, 2012, p. 45). Para tanto, propõe atividades que atendem a diferentes objetivos que o professor poderá selecionar, adaptar e complementar de acordo com os conteúdos curriculares visados.

Ainda com relação aos dicionários infantis, Humblé (2011) suspeita que o fato de apresentarem poucas palavras desconhecidas pe-

Educação \& Realidade, Porto Alegre, v. 43, n. 1, p. 313-336, jan./mar. 2018.

327 
las crianças pode indicar que seu propósito principal não é esclarecer significados, mas simbolizar a intenção dos governantes de melhorar a qualidade do ensino pela apresentação de um novo objeto de conhecimento. Possenti (2012), com quem concordamos, coloca em dúvida a eficácia dos dicionários infantis e propõe que se compare o mesmo verbete em um dicionário completo e em outro infantil para que se visualize o equívoco de fazer a criança acreditar que a palavra tenha apenas um ou dois sentidos, sem explorar a polissemia e o funcionamento discursivo.

Para Silva-Rodrigues e Pacífico (2007, p. 58), a não exploração da polissemia é intencional:

[...] visto que esta rompe com o que se tem de garantido, com o historicamente acumulado, abre espaço para a subjetividade; a paráfrase, sim, é enaltecida pela maioria da instituição escolar, pois demonstra estabilidade, segurança - a ilusão da verdade sedimentada. Esta verdade tem mais prestígio, ainda, se vier regulada pelas normas gramaticais e ortográficas.

Ainda tendo em vista a questão da polissemia, na tabela abaixo tomamos como exemplo o adjetivo cru nos dicionários Caldas Aulete (Geiger, 2011a; 2011b; 2011c; 2011d), o único com títulos nas quatro categorias do PNLD Dicionários 2012.

\section{Tabela 1 - Verbete cru em Dicionários do Tipo 1 a 4}

\begin{tabular}{|c|c|}
\hline $\begin{array}{l}\text { Tipo } 1 \\
1.000 \text { verbetes }\end{array}$ & $\begin{array}{l}\text { Um alimento cru não foi cozido, ou não está completamente cozido. } \\
\text { [O contrário de cru é cozido.] (Geiger, 2011a, p. 57). }\end{array}$ \\
\hline $\begin{array}{l}\text { Tipo } 2 \\
6.183 \text { verbetes }\end{array}$ & 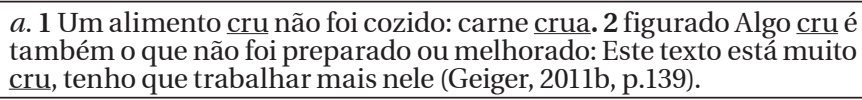 \\
\hline $\begin{array}{l}\text { Tipo } 3 \\
29.431 \text { verbetes }\end{array}$ & $\begin{array}{l}\text { a. } 1 \text { Que não está cozido (peixe cru). } 2 \text { Não preparado (couro cru) } 3 \text { Fig. } \\
\text { Inexperiente: Onovo funcionário ainda está muito cru. [Fem.: crua.] [F.; } \\
\text { Do lat. crudus, a, um.]. (Geiger, 2011c, p.238) }\end{array}$ \\
\hline $\begin{array}{l}\text { Tipo } 4 \\
75.756 \text { verbetes }\end{array}$ & $\begin{array}{l}\text { a. } 1 \text { Que não está cozido: Não gosto desashimi, porque não gosto de peixe } \\
\text { cru. [Ant.: cozido] } 2 \text { Não suficientemente cozido: Passe mais este bife, } \\
\text { ainda está cru. } 3 \text { Diz-se do que está em estado natural, que não foi pre- } \\
\text { parado em qualquer processo especial, como curtição, tingimento, etc. } \\
\text { (couro cru, linho cru) } 4 \text { Que não sofreu qualquer processo ou interfe- } \\
\text { rência quelhe diminuísse a intensidade, o brilho etc.: Nenhuma nuvem } \\
\text { toldava a crua luz do meio dia. } 5 \text { Fig. Inexperiente, imaturo: Ele ainda } \\
\text { está muito cru para manejar essa máquina. [Ant.: experiente, maduro] } 6 \\
\text { Ainda em fase inicial, não elaborado o bastante; INCIPIANTE: Este texto } \\
\text { ainda está muito cru, é preciso trabalha-lo mais. } 7 \text { Sem disfarce ou fingi- } \\
\text { mento: Disse a verdade nua e crua. [Ant.: disfarçado] 8 Sem delicadeza, } \\
\text { eufemismo ou polimento (palavras cruas); ASPERO, BRUTO, RISPPIDO } \\
\text { [Ant.: delicado, gentil, suave.] } 9 \text { Cruento, sanguinolento, bárbaro (guerra } \\
\text { crua) [Ant.: incruento.] } 10 \text { Aflitivo, angustiante, penoso: "E foi que, de } \\
\text { doença crua e feia, a mais que eu nunca vi... (Luís de Camões, Os Lusí- } \\
\text { adas (Canto V)) [Ant.: suportável, tolerante.] 11 Escandaloso, chocante } \\
\text { (linguagem crua) [Fem.: crua] } \text { a2g2n. } 12 \text { Que é da cor do material de } \\
\text { que é feito em estado natural (vestido cru, bolsas cru) 13 Diz-se dessa } \\
\text { cor: lençol de cor cru. sm. } 14 \text { Lus. Em Portugal, óleo cru, petróleo em } \\
\text { estado bruto [F.: Do lat. crudus Hom./Par.: (pl) crus, cruz (sf.). A - Sem } \\
\text { dissimulação ou disfarce. Estar/ser } \text { em Não ter conhecimento sobre, } \\
\text { não estar preparado em (Geiger, 2011d, p. 421). }\end{array}$ \\
\hline
\end{tabular}

Fonte: Elaboração própria a partir dos dicionários indicados. 
Pode ser observado que na passagem de um tipo a outro não se acrescentam apenas novos significados - de 1 para 14 -, ocorre também um aumento de informações metalinguísticas, entre as quais se destacam a classe gramatical, indicando como adjetivo a partir do Tipo 2, a flexão de gênero, indicada nos tipos 3 e 4 como fem. crua, o uso conotativo em expressões de sentido figurado, entre outros aspectos presentes no verbete transcrito do dicionário de Tipo 4 (Geiger, 2011d), que deixa subentendido que tais informações sejam adequadas apenas aos alunos do ensino médio, a quem se destinam.

Portanto, de acordo com Rangel, podemos concluir que o PNLD espera dos dicionários selecionados caráter quase tão didático quanto o do livro. Nesse sentido, à semelhança do que ocorreu com o livro didático, o PNLD se tornou fonte de referência e modelo para a produção editorial de dicionários escolares. Por sua vez, os princípios e critérios de avaliação para os dicionários repercutiram sobre os livros didáticos de língua portuguesa que passaram a apresentar com mais frequência atividades de reflexão sobre o vocabulário, muitas vezes com remissões ao uso de dicionários.

Prevendo dificuldades pelo reduzido número de entradas em algumas obras do acervo, uma das orientações é quanto à verificação antecipada por parte do professor de que todas as palavras a serem pesquisadas pelos alunos constem dos dicionários, pois a qualidade e a adequação dos dicionários "dependem do quanto estejam afinados aos objetivos e ao público do ensino fundamental e, portanto, aos seus alunos e professores" (Rangel, 2012, p. 28).

O Guia sugere como ponto de partida para a seleção das atividades, o levantamento da abordagem lexicográfica do livro didático adotado. Dessa maneira, as atividades propostas pelo referido documento poderiam se diferenciar complementando ou expandindo o trabalho proposto pelo livro didático.

Após a mudança de composição dos acervos, com um exemplar de cada título, o Guia Dicionários em Sala de Aula passou a priorizar a utilização desse material em sala de aula onde estão disponíveis à consulta dos alunos. Assim, ampliar o quadro tipológico de obras disponíveis aos alunos reverteria à ideia absoluta dos minidicionários como única opção de dicionário escolar, o que vai ao encontro da ideia de que "não há uma categoria específica de dicionário escolar, mas dicionários adequados para a escola” (Krieger, 2006, p. 238).

No entanto, a mudança do acervo leva a problematizar se tais títulos - dado o reduzido número de entradas nos acervos de Tipo 1 e Tipo 2 (500 a 15000 palavras) - são adequados às demandas do público ao qual se direcionam, alunos do primeiro ciclo do EF. Que verbetes registram? Que verbetes excluem? Quais são as possiblidades que tais acervos dão para o trabalho do professor em sala de aula? ${ }^{4}$

Em nossos estudos, percebemos que nem sempre a proposta responde às expectativas criadas. Vale lembrar o que destaca Batista (2003) sobre a existência de descompasso entre as expectativas dos professo- 
res e do PNLD sobre o que seja um livro adequado às práticas de sala de aula. Com os dicionários ocorre o mesmo e, maior que o descontentamento dos professores que não participaram da escolha dos títulos, está a insatisfação dos alunos, consulentes destas obras, que apresentam queixas frequentes sobre a ausência de palavras pesquisadas. Tal fato pôde ser observado a partir do registro e análise das impressões de cerca de 50 alunos do $5^{\circ}$ ano do EF de uma escola pública do interior do estado de São Paulo. Destacamos aqui algumas dessas impressões.

Inicialmente os projetos gráficos diferenciados dos dicionários do acervo despertam nas crianças o encantamento próprio das obras literárias mais sedutoras por meio do apelo de ilustrações conhecidas, como os personagens do Sítio do Pica Pau Amarelo (Geiger, 2011a) ou da Turma do Cocoricó (Geiger, 2011b). No entanto, quando devem buscar por um verbete específico, os alunos começam a perceber que, na maioria das vezes, é preciso consultar vários títulos disponíveis até localizarem o que procuram, pois nos dicionários de Tipos 1 e 2 há uma redução de entradas e sentidos em cada verbete. A proposta original de adequação da linguagem nas obras destinadas aos alunos das séries iniciais do EF limitou-se a simplificá-la demasiadamente e a acrescentar ilustrações.

Como ainda não dominam totalmente a ordem alfabética e/ou não estão absolutamente seguros quanto a esse domínio, os alunos insistem na busca por palavras que muitas vezes os dicionários do acervo não registram, ocasionando grande perda de tempo gerada pela incerteza acerca da ausência da palavra ou da dificuldade em encontrá-la (Colombo, 2014).

Ainda com relação às dificuldades que os alunos encontraram para realizar as atividades propostas, nossas observações sugerem que a falta de domínio metalinguístico também se constitui em obstáculo para sua execução. Dentre elas, a atividade Igual, mas diferente... (Rangel, 2012, p. 59) propõe a busca por palavras homônimas (verbo/substantivo) no contexto de frases pré-definidas como Não gosto do João, ele sempre manga muito de mim! ou Adoro música, mas não canto muito bem, em que as palavras a serem pesquisadas são os verbos mangar e cantar. Por exigir reflexão mais elaborada acerca da linguagem - função, classe gramatical e relação sintática entre determinadas palavras de uma frase -, a complexidade da atividade para o aluno ainda no ciclo I do EF é maior do que muitas vezes se prevê. Se o vocábulo pesquisado é um verbo, o consulente só aprenderá a localizá-la se souber o que é verbo e que nos dicionários essa classe de palavras é arrolada pelo infinitivo.

Estes aspectos podem ser problematizados a partir da situação vivenciada por uma dupla de alunas de $5^{\circ}$ ano do EF, quando procuravam no dicionário a palavra vela, tendo como referência a frase $O$ soldado vela pela segurança do palácio:

L. - Agora é qual?

M. - Vela (começam a procurar no dicionário).

330 Educação \& Realidade, Porto Alegre, v. 43, n. 1, p. 313-336, jan./mar. 2018. 
L. - Deixa eu ver "vela pela segurança do palácio" (lê a frase dada na atividade e le "vela" - substantivo - no dicionário).

M. - Tem outra vela, sem ser isso?

L. - Ó, tem duas velas, mas eu já li a vela 2 e a vela 1 . Na vela 2 tem "peça cilíndrica ou de outros formatos..." e na vela 1 tem "peça de lona ou de brim...".

(Ambas seguem em silêncio a sequência de entradas do dicionário e localizam o verbo velar. Leem juntas em voz alta).

L. e M. - Velar 1: "cobrir com véu, esconder tapando, escurecer, tornar-se secreto, ocultar". Velar 2: "passar a noite acordado [...]" (interrompem a leitura).

L. - (Com entusiasmo) Ah! Eu acho que é esse! (as duas riem felizes com a descoberta).

M. - Qual que é o velar?

L. - É esse daqui, ó (ainda sorrindo), é igualzinho.

M. - (repetindo devagar, enquanto copiam) "Passar a noite acordado". 2"Estar alerta, vigiar".

Apesar de as alunas terem chegado à resposta esperada, a análise da atividade das duas alunas demonstrou que não houve reflexão sobre a função da palavra na frase, e sim leitura em sequência das entradas do dicionário que conduziu à resposta correta: vela 1 , vela 2 , velame, velar 1 e velar 2.

Para essa atividade, o Guia Dicionários em Sala de Aula (Rangel, 2012) traz observação relevante sobre o trabalho com classes de palavras indicando que o professor mostre que as palavras aparecem da mesma forma na frase e no dicionário quando são substantivos; já, quando são verbos, o dicionário só registra os infinitivos. Embora essas informações tenham sido passadas aos alunos, tiveram pouca valia na execução da atividade, já que falta a eles a sistematização de tais análises linguísticas.

O máximo de proveito no uso do dicionário é atingido pelo leitor que compreende como funciona a língua e tem conhecimentos linguísticos para entender sua descrição. Para que o aluno tire o melhor proveito das informações contidas nos verbetes e do grau de aprofundamento gramatical dos dicionários, ele precisa ter oportunidade para aprofundar e sistematizar esse conhecimento, trabalho que deveria ser contemplado também pelo livro didático, material complementar no PNLD.

O livro didático adotado para as turmas pesquisadas foi A Aventura do Saber (Ferronato; Silva, 2011), do triênio 2013-2015 do PNLD, que traz uma única atividade que menciona a utilização do dicionário, propondo o trabalho de produção de frases com os diferentes sentidos de um verbete de dicionário. Além dessa proposta, não há no livro nenhum subsídio que auxilie o aluno na pesquisa ao dicionário, como atividades sobre ordem alfabética, verbos no infinitivo ou flexão em número, gênero e grau, tornando inviável ao professor articular as atividades desses dois recursos do PNLD: livro didático e dicionário. As unidades do livro são organizadas pelo eixo temático e, por isso, não seguem nenhuma sequência prévia dos conteúdos, apresentando aspectos gramaticais de acordo com as análises possíveis nos textos apresentados. 
O reduzido número de verbetes também pode dificultar o trabalho do professor e dos alunos. Sabemos que é impossível que um dicionário traga todas as palavras de uma língua viva, em constante modificação. Porém, não há justificativa para que o dicionário de uso escolar não apresente vocábulos como os do Hino Nacional Brasileiro - fúlgido, garrido e lábaro - para privilegiar em suas reduzidas entradas palavras como copo, faca e limão que, mesmo para leitores e escritores iniciantes, não oferecem dúvidas quanto à grafia, não possuem acento gráfico e são próprias do vocabulário ativo desses alunos. Consideramos, então, a necessidade de maior cuidado, a revisão e a adequação dos livros didáticos e dicionários, para que, cada vez mais, se tornem instrumentos adequados para a organização do trabalho do professor e o aprendizado do aluno.

Apesar da qualidade do Guia Dicionários em Sala de Aula, que atinge seus objetivos de oferecer suporte teórico e prático, ao indicar atividades que conduzem para além do tradicional uso do dicionário para tirar dúvidas de ortografia e buscar significados desconhecidos, tais discrepâncias entre os parâmetros do PNLD, o guia e os dicionários propriamente ditos, sugerem aos responsáveis pelo programa a necessidade de maior cuidado na avaliação das obras a serem aprovadas.

\section{Considerações Finais: como as orientações podem dialogar com o professor?}

Com o objetivo de compreender as relações entre as orientações do livro didático e o trabalho do professor, ao longo deste artigo, argumentamos em favor da análise do contexto de produção do livro didático e das implicações das orientações dos manuais para o trabalho do professor. Nesse sentido, destacamos a necessidade de que os gestores e avaliadores do PNLD olhem para além do próprio livro e estejam mais atentos à adequação entre as orientações dos manuais e as propostas dos livros didáticos e aos efeitos das orientações dos manuais com relação às reais condições para a organização do trabalho docente em sala de aula.

Se a presença dos livros didáticos é marcante em sala de aula, muito se deve a programas como o PNLD, o Programa Nacional do Livro Didático, que, ao mesmo tempo em que busca garantir e universalizar o acesso ao livro didático, acaba por determinar o modo de elaboração do mesmo. Dentre as muitas vozes que ecoam no livro didático, a voz do PNLD é muito forte, numa tentativa das editoras de ter suas obras aprovadas, diante do mercado bastante rentável que é o de livros didáticos no Brasil. O professor parece ser o interlocutor declarado, mas não o interlocutor real, lugar este que é ocupado pelos avaliadores do Programa. A distância e o desencontro entre o interlocutor real e o imaginado também pode ser causa da distância que encontramos entre o manual do professor dos livros didáticos e o que de fato encontramos nas atividades dirigidas aos alunos em sala de aula. 
Com relação ao PNLD Dicionários, questões como as aqui indicadas explicitam que, embora o Guia traga sugestões de atividades interessantes e exequíveis, estas não foram pensadas tendo como foco os dicionários disponíveis nos acervos, por isso, nem sempre estão adequadas ao que essas obras oferecem. A constituição do acervo com títulos diferentes não considera momentos em que seria mais significativo ao processo de aprendizagem que todos os alunos da turma utilizassem dicionários iguais. Além disso, o reduzido número de exemplares dificulta o desenvolvimento de atividades coletivas, e a necessidade de mediação constante do professor não favorece a autonomia do aluno.

Considerando as análises apresentadas, ressaltamos também que as propostas dos livros didáticos podem repercutir no professor de forma muito mais profunda e estendida, indo muito além do uso pontual em sala de aula, uma vez que esse material tem/teria o potencial de provocar reflexões sobre suas concepções e práticas educativas. Ou seja, é fundamental considerar como o professor que segue as orientações de um livro didático pode compreender as concepções veiculadas, a escolha de determinados conteúdos, sequências e procedimentos de ensino, no lugar de outras possibilidades. Foi possível indicar que nos livros analisados ainda predominam propostas de ensino que reproduzem aquilo que o professor já conhece e faz usualmente em sala de aula. Assim, além de legitimar e reiterar determinadas práticas educativas, principalmente pela centralidade que ocupam na organização do trabalho didático, é necessário problematizar como os livros didáticos podem contribuir para que o professor construa e efetive práticas mais adequadas às características e necessidades de seus alunos.

Dessa forma, em termos do processo de alfabetização e do ensino de Língua Portuguesa, cabe indagar: como os livros didáticos podem tematizar os diferentes usos sociais, as especificidades da linguagem escrita, o funcionamento discursivo, dentre muitos outros aspectos a serem ensinados na escola? Acreditamos que para isso é importante considerar o professor e os alunos como interlocutores e protagonistas primordiais, bem como assumir o contexto escolar como espaço dos processos polissêmicos da linguagem, de produção e de circulação dos mais variados textos socialmente produzidos.

Recebido em 11 de junho de 2016 Aprovado em 03 de março de 2017

\section{Notas}

1 Informações detalhadas sobre o PNLD e seu funcionamento estão disponíveis em <http://www.fnde.gov.br/programas/livro-didatico/livro-didatico-funcionamento $>$.

2 Os editais e documentos relacionados ao processo de inscrição e avaliação estão disponíveis no site do FNDE. Descrição e análise deste processo pode ser encontrada em Silva (2015).

3 A respeito da análise da publicação dos livros didáticos no contexto do mercado editorial brasileiro, sugere-se consultar Britto (2011) e Mello (2012).

Educação \& Realidade, Porto Alegre, v. 43, n. 1, p. 313-336, jan./mar. 2018. 
4 Esta discussão é aprofundada por Colombo (2014) em pesquisa acerca do uso de dicionários por alunos do ensino fundamental.

\section{Referências}

AMIGUES, René. Trabalho do professor e trabalho de ensino. In: MACHADO, Anna Rachel (Org.). O Ensino Como Trabalho: uma abordagem discursiva. Londrina: Eduel, 2004. P. 35-53.

BAKHTIN, Mikhail Mikhailovich. Marxismo e Filosofia da Linguagem. Tradução de M. Lahud e Y.F. Vieira. São Paulo: Hucitec, 2004.

BATISTA, Antônio Augusto Gomes. A Avaliação dos Livros Didáticos: para entender o Programa Nacional do Livro Didático (PNLD). In: ROJO, Roxane; BATISTA, Antônio Augusto Gomes (Org.). Livro Didático de Língua Portuguesa, Letramento e Cultura Escrita. Campinas: Mercado das Letras, 2003. P. 25-67.

BATISTA, Antônio Augusto Gomes; ROJO, Roxane. Livros Escolares no Brasil: a produção científica. In: COSTA VAL, Maria da Graça; MARCUSCHI, Beth (Org.). Livros Didáticos de Língua Portuguesa: letramento, inclusão e cidadania. Belo Horizonte: Ceale; Autêntica, 2008. P. 13-45.

BRAGANÇA, Angiolina; CARPANEDA, Isabella. Porta Aberta: letramento e alfabetização, $1^{\circ}$ ano. São Paulo: FTD, 2011.

BRASIL. Guia de Livros Didáticos PNLD 2004: dicionários. Brasília: Ministério da Educação, Secretaria de Educação Fundamental, 2003.v. 4. Disponível em: <http:// portal.mec.gov.br/seb/arquivos/pdf/volume4.pdf>. Acesso em: $10 \mathrm{dez} .2014$.

BRASIL. Guia de livros didáticos PNLD 2013: letramento e alfabetização - língua portuguesa, ensino fundamental, anos iniciais. Brasília: Ministério da Educação, Secretaria de Educação Básica, 2012. Disponível em: <http://www.fnde. gov.br/programas/livro-didatico/guia-do-livro/item/3773-guia-pnld-2013-\%E2\%80\%93-ensino-fundamental>. Acesso em: 2 mar. 2013.

BRITTO, Tatiana Feitosa de. O Livro Didático, o Mercado Editorial e os Sistemas de Ensino Apostilados: textos para discussão. n. 92. Brasília: Centro de Estudos da Consultoria do Senado, Senado Federal, 2011. P. 3-19. Disponível em: <http://wwwl2.senado.gov.br/publicacoes/estudos-legislativos/tipos-de-estudos/textos-para-discussao/td-92-o-livro-didatico-o-mercado-editorial-e-os-sistemas-de-ensino-apostilados>. Acesso em: 10 dez. 2015.

CLOT, Yves. A função psicológica do Trabalho. Petrópolis: Vozes, 2006.

COLOMBO, Silmara Regina. Com a Palavra o Consulente: a opinião dos alunos sobre os dicionários do PNLD. Uniletras, Ponta Grossa, v. 36, n. 2, p. 225-234, jul./dez. 2014.

COLOMBO, Silmara Regina. Consulta ao Dicionário: das prescrições para o professor ao uso em sala de aula. 2016. 125 f. Dissertação (Mestrado em Educação) - Faculdade de Filosofia, Ciências e Letras de Ribeirão Preto, Universidade de São Paulo, Ribeirão Preto, 2016.

FERREIRA, Anise D'Orange. Considerações sobre o Contexto do Trabalho Docente com Tecnologias Digitais. In: MACHADO, Anna Rachel; LOUSADA, Eliane Gouvêa; FERREIRA, Anise D'Orange (Org.). O Professor e Seu Trabalho: a linguagem revelando práticas docentes. Campinas: Mercado das Letras, 2011. P. 29-59. FERREIRA, Aurélio Buarque Holanda. Mini Aurélio Século XXI: o minidicionário da língua portuguesa. Rio de Janeiro: Nova Fronteira, 2001.

FERRONATO, Vera Lúcia; SILVA, Célia Cris. A Aventura do Saber: Língua Portuguesa $-5^{\circ}$ ano. São Paulo: Leya, 2011.

334 Educação \& Realidade, Porto Alegre, v. 43, n. 1, p. 313-336, jan./mar. 2018. 
Nogueira; Silva; Colombo

FREITAG, Bárbara; MOTTA, Valéria; COSTA, Wanderly. O Livro Didático em Questão. São Paulo: Cortez Editora, 1989.

GEIGER, Paulo (Org.). Meu Primeiro Dicionário Caldas Aulete com a Turma do Cocoricó. São Paulo: Globo, 2011a.

GEIGER, Paulo (Org.). Caldas Aulete: dicionário escolar da língua portuguesa ilustrado com a turma do Sítio do Pica-Pau Amarelo. São Paulo: Globo, 2011b.

GEIGER, Paulo (Org.). Caldas Aulete: minidicionário contemporâneo da língua portuguesa. Rio de Janeiro: Lexikon, 2011c.

GEIGER, Paulo (Org.). Novíssimo Aulete: dicionário contemporâneo da língua portuguesa. Rio de Janeiro: Lexikon, 2011d.

GERALDI, João Wanderley. Portos de Passagem. São Paulo: Martins Fontes, 1997.

HUMBLÉ, Philippe René Marie. Um começo de conversa. In:XATARA, Cláudia; BEVILACQUA, Cleci Regina; HUMBLÉ, Philippe René Marie (Org.). Dicionários na Teoria e na Prática: como e para quem são feitos. São Paulo: Parábola Editorial, 2011. P. 9-13.

KRIEGER, Maria da Graça. Políticas Públicas e Dicionários para Escola: o programa nacional do livro didático e seu impacto sobre a lexicografia didática. Cadernos de Tradução, v. 2, n. 18, Florianópolis, Universidade Federal de Santa Catarina, p. 235-252, 2006.

LERNER, Delia. O Livro Didático e a Transformação do Ensino da Língua. In: BATISTA, Antônio Augusto Gomes; COSTA VAL, Maria da Graça (Org.). Livros de Alfabetização e de Português: os professores e suas escolhas. Belo Horizonte: Autêntica, 2004. P. 115-136.

MACHADO, Anna Rachel. Por uma concepção ampliada do trabalho do professor. In: GUIMARÃES, Ana Maria de Mattos; MACHADO, Anna Rachel; COUTINHO, Antônia (Org.). O Interacionismo Sociodiscursivo: questões epistemológicas e metodológicas. Campinas: Mercado das Letras, 2007. P. 77-97.

MACHADO, Anna Rachel; ABREU-TARDELLI, Lília Santos. Textos Prescritivos da Educação Presencial e a Distância: fonte primeira do estresse do professor?. In: CRISTOVÃO, Vera Lúcia Lopes; ABREU-TARDELLI, Lília Santos (Org.). Linguagem e Educação: o trabalho do professor em uma nova perspectiva. Campinas: Mercado de Letras, 2009. P. 101-116.

MARTINS, Eliecília de Fátima; SALES, Norma Almeida de Oliveira; SOUZA, Cléber Alves. O Estado, o Mercado Editorial e o Professor no Processo de Seleção dos Livros Didáticos. Estudos em Avaliação Educacional, São Paulo, v. 20, n. 42, p. 11-26, jan./abr. 2009.

MELLO, Gustavo. Desafios para o Setor Editorial Brasileiro de Livros na Era Digital. BNDES Setorial, Rio de Janeiro, Banco Nacional do Desenvolvimento, n. 36, p. 429-473, set. 2012. Disponível em: <http://www.bndes.gov.br/SiteBNDES/export/sites/default/bndes_pt/Galerias/Arquivos/conhecimento/bnset/set3612.pdf>. Acesso em: $10 \mathrm{dez} 2015$.

MIRANDA, Cláudia; MICARELLO, Hilda; SCHAPPER, Ilka. Viraver: letramento e alfabetização, $1^{\circ}$ ano. São Paulo: Scipione, 2011.

POSSENTI, Sírio. A reinvenção do dicionário mirim. Revista Língua Portuguesa, São Paulo, Segmento, n. 83, 2012.

RANGEL, Egon de Oliveira. Dicionários Escolares e políticas públicas em educação: a relevância da "Proposta Lexicográfica". IN: CARVALHO, Orlene Lúcia de Sabóia; BAGNO, Marcos (Org.). Dicionários Escolares: políticas, formas e usos. São Paulo: Parábola Editorial, 2011. P. 37-60.

RANGEL, Egon de Oliveira. Com Direito à Palavra: dicionários em sala de aula. Brasília: Ministério da Educação, Secretaria de Educação Básica, 2012.

Educação \& Realidade, Porto Alegre, v. 43, n. 1, p. 313-336, jan./mar. 2018 
ROMÃO, Lucília Maria Sousa; PACÍFICO, Soraya Maria Romano. O Canto e o (En)canto do Sabiá: movimentos entre aqui e lá. In: ROMÃO, Lucília Maria Sousa; PACÍFICO, Soraya Maria Romano. Era uma Vez, uma Outra História: leitura e interpretação na sala de aula. São Paulo: DCL, 2006. P. 63-76.

SAUJAT, Frédéric. O Trabalho do Professor nas Pesquisas em Educação: um panorama. In: MACHADO, Anna Rachel (Org.). O Ensino como Trabalho: uma abordagem discursiva. Londrina: Eduel, 2004. P. 3-34.

SILVA, Maísa Alves. "Pela mediação da aprendizagem em sala de aula": as orientações aos professores nos livros didáticos do $1^{\circ}$ ano do Ensino Fundamental. 2015. 131 f. Dissertação (Mestrado em Educação) - Faculdade de Filosofia, Ciências e Letras de Ribeirão Preto, Universidade de São Paulo, Ribeirão Preto, 2015.

SILVA, Maísa Alves; NOGUEIRA, Ana Lúcia Horta. Como os Livros Didáticos de Alfabetização Contemplam os Diferentes Percursos de Aprendizagem?. Olh@ ares, Guarulhos, v. 3, n. 2, p. 119-132, 2015.

SILVA-RODRIGUES, Elídia de Souza; PACÍFICO, Soraya Maria Romano. Investigações Sobre Autoria em Textos Produzidos por Alunos da $4^{\text {a }}$ Série do Ensino Fundamental. In: PACÍFICO, Soraya Maria Romano; ROMÃO, Lucília Maria Sousa. Leitura e Escrita: no caminho das linguagens. Ribeirão Preto: Editora Alphabeto, 2007. P. 49-77.

Ana Lúcia Horta Nogueira possui doutorado em Educação pela Universidade Estadual de Campinas (2001) e pós-doutorado em Linguística Aplicada pela UNICAMP (2006) e em Psicologia pela Clark University (2013). É professora do Departamento de Psicologia Educacional da Faculdade de Educação da UNICAMP e pesquisadora do Grupo de Pesquisa Pensamento e Linguagem (Faculdade de Educação - UNICAMP). No período de 2014-2017, contou com apoio da FAPESP - Fundação de Amparo à Pesquisa do Estado de São Paulo, na modalidade Auxílio à Pesquisa (2014/070386).

E-mail: alhnog@unicamp.br

Maísa Alves Silva possui graduação em Pedagogia e Mestrado em Educação pela Faculdade de Filosofia, Ciências e Letras de Ribeirão Preto - Universidade de São Paulo (USP), desenvolvendo pesquisas com temas relacionados à didática, desenvolvimento infantil e trabalho do professor. Bolsista de Mestrado da FAPESP - Fundação de Amparo à Pesquisa do Estado de São Paulo, no período de 2013 a 2015 (Processo 2013/17591).

E-mail: maalvessilva@hotmail.com

Silmara Regina Colombo graduada em letras pelo Centro Universitário Barão de Mauá (Português-Inglês) e pela Universidade Metropolitana de Santos (Português-Espanhol). Possui Mestrado em educação pela Faculdade de Filosofia Ciências e Letras de Ribeirão Preto - Universidade de São Paulo (USP). Atualmente é professora da rede pública de ensino, atuando na área de ensino de Português no Ensino Médio (SEE-SP) e na Secretaria de Educação de Sertãozinho-SP como técnica pedagógica.

E-mail: silmaracolombo@live.com 